\title{
Bolt Spacing and End Distance of Bolted Connection of Laminated Veneer Lumber (LVL) Sengon
}

\author{
Awaludin, A. ${ }^{* *}$ and Saputro, D.N. ${ }^{2}$
}

\begin{abstract}
This paper focuses on bolt connections on Laminated Veneer Lumber (LVL) Sengon. Series of connection tests were conducted to evaluate $3.5 d, 5 d$, and $7 d$ end distances and $3 d, 4 d$, and $5 d$ bolt spacings, where $d$ is a $10 \mathrm{~mm}$ bolt diameter. All connections were double-shear model (steel-LVL-steel). The results showed that all variations of end distance failed in ductile manner especially the connections with end distances of $5 d$ and $7 d$. Load carrying capacity of the connections with end distances of $5 d$ and $7 d$ were about the same. For single bolt connections, those with $5 d$ bolt spacing had the highest ratio of load carrying capacity. Only the two-bolt connections with $5 d$ bolt spacing gave the ratio of load carrying capacity higher than that of prediction. These findings therefore suggests that minimum end distance of $5 d$ and minimum bolt spacing of $5 d$ are recommended to be addopted in LVL Sengon bolted connections.
\end{abstract}

Keywords: Bolt spacing; end distance; load carrying capacity; LVL Sengon; timber joints.

\section{Introduction}

Laminated Veneer Lumber (LVL) Sengon (Paraserianthes falacataria) has recently come to Indonesian markets as one of new emerging and green building materials. It is one type of engineered wood products and it is produced by gluing veneers of Sengon timber under 0.6-0.7 MPa pressure and 105$110{ }^{\circ} \mathrm{C}$ temperature [1]. It is more homogenous and has better mechanical properties compared to solid Sengon timber. A series of works to develop design guideline has been conducted by the first author since a couple years ago to further utilize this LVL Sengon in practical applications $[2,3]$.

One of the most important element and the weakest link of timber structures is connection. Among several types of timber connections available, doweltype connections, using bolt or nails, or wooden dowels are the most common in practice. Many timber researchers and engineers have devoted their works to investigate various issues about dowel-type connections: load carrying capacity [4-7];

\footnotetext{
1 Research Group of Innovative Sustainable Infrastructure Materials and Construction Technologies, Department of Civil and Environmental Engineering, Universitas Gadjah Mada, Jalan Grafika 2, Sleman, Yogyakarta 55281, INDONESIA

2 Civil Engineering Study Program, Faculty of Engineering, University of Muhammadiyah Purwokerto, Jalan Dukuh Waluh, Purwokerto 53182, INDONESIA

* Corresponding author; e-mail: ali.awaludin@ugm.ac.id
}

Note: Discussion is expected before June, 1 ${ }^{\text {st }} 2017$, and will be published in the "Civil Engineering Dimension", volume 19, number 2, September 2017.

Received 24 July 2016; revised 19 October 2016; accepted 15 December 2016. cyclic and dynamic performances [8,9]; and strengthening [10-12]. According to European Yield Model (EYM) developed by Johansen [4], load carrying capacity of timber connection is governed by bending strength of the bolt, bearing properties of the timber member, and connection geometry. EYM was developed based on a connection model having one steel dowel; therefore, EYM does not consider load carrying capacity of the connection failed due to wood row-tear-out or group-tear-out that commonly found in multiple-bolt connections.

According to the Indonesian Timber Construction Standard, connectors such as bolts should be placed with the minimum end distance of $5 d$ (hardwood species) and minimum bolt spacing of $4 d$ where $d$ is the bolt diameter. Thus, it is interesting to evaluate whether this requirement, which is generally accepted for solid timber, is also applicable to LVL members or has to be modified. This paper is aimed to determine minimum end distance and bolt spacing when LVL Sengon is used so that evaluation of load carrying capacity given by EYM is still applicable.

\section{Dowel-type Timber Connections}

Dowel-type connection covers bolts, dowel, and nail fasteners. This connection transfers the applied load through a combination of bearing resistance of wood fibers beneath the fastener and bending resistance of the dowel. Formulation of load carrying capacity of timber joint has been proposed few decades ago by Johansen [4], later known as EYM, which is very straight forward though it underestimates the actual load carrying capacity. EYM formulation of load 
carrying capacity of dowel-type timber connections can be found easily in many text books and design standards. In the case of double-shear joints such as steel-wood-steel, possible load carrying capacities of the connection $(Z)$ along with its failure modes are summarized in Table 1 , where $F_{\mathrm{e}}$ is the dowel bearing strength of timber, $t$ the wood member thickness, $d$ and $M_{y b}$ are diameter and bending yield moment of bolt, respectively.

Table 1. Possible Failure Modes and Its Load Carrying Capacity of Steel-Wood-Steel Bolted Joints

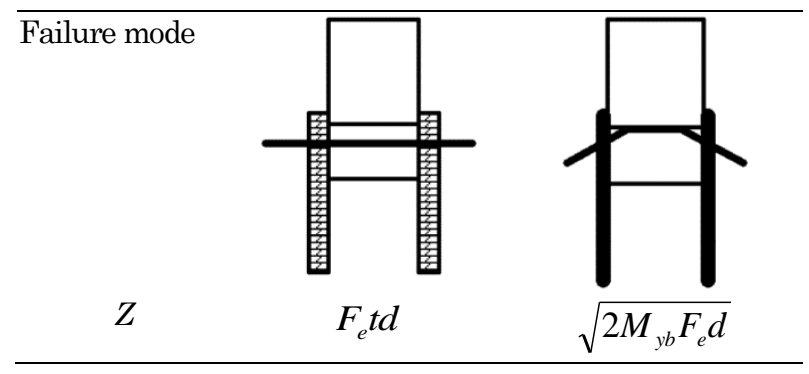

Several years after EYM was adopted, numerical solution by means of finite element analysis (FEA) based on theory of beam on elastic foundation was proposed to evaluate load carrying capacity of timber joints [5,13]. This second method somehow is more elegant compared to EYM as it provides information about load-slip curve of the joint so that both load carrying capacity and load-slip modulus of the connection will be attained at the same time. This method utilizes analytical solution of beam on elastic foundation incooperated with the general procedure of FE analysis instead of standard polynomial functions.

Those two above mentioned formulations given in Table 1 are valid only when early splitting of timber or row shear and group-tear-out of a line of fasteners is prevented by providing sufficient end distance and bolt spacing (see Fig. 1). In multiple bolt connection, uneven load distribution among the fasteners due to various aspects such as imperfection of lead-hole fabrication, non-homogenous and orthotropic timber properties, group action factor will apply. This informs that the load carrying capacity of connection consists of multiple bolts is less than the product of load carrying capacity of single bolt and the number of bolts. Jorissen [6] proposed Equation 1 to evaluate effective number of fasteners $\left(n_{e f}\right)$ when more than one fastener are placed in one line with fastener spacing $a_{1 .}$

$n_{e f}=n^{0.9} \sqrt[4]{\frac{a_{1}}{13 d}}$

where $n$ is number of fastener, and $d$ is fastener diameter.
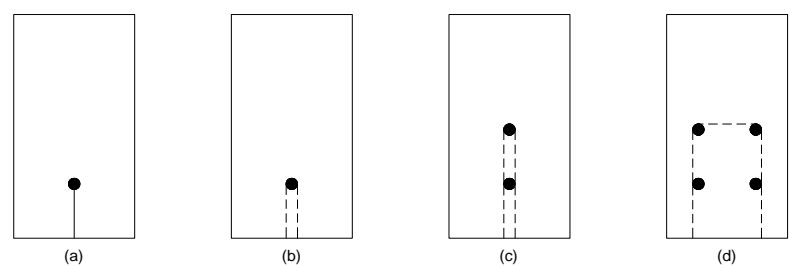

Figure 1. Possible Failure Modes of Bolted Timber Joints: a) Splitting; b) and c) Row Shear; and (d) Group-tear-out

\section{Materials and Test Methods}

LVL members used in this study had a cross section of $80 \mathrm{~mm}$ by $120 \mathrm{~mm}$, an average moisture content of $11 \%$, and density of $316 \mathrm{~kg} / \mathrm{m}^{3}$. Figure 2 shows a double-shear connection model where two steel plates of $5 \mathrm{~mm}$ thick were used as side members of the connection and are fastened using $10 \mathrm{~mm}$ diameter bolts. The applied load and connection slip were continuously measured until the connection load decreased by $20 \%$ of the maximum load. Two LVDT displacement transducers were deployed as shown in the connection test set-up shown in Fig. 2a to measure connection slip, which is the relative displacement between the steel plate and the LVL members.

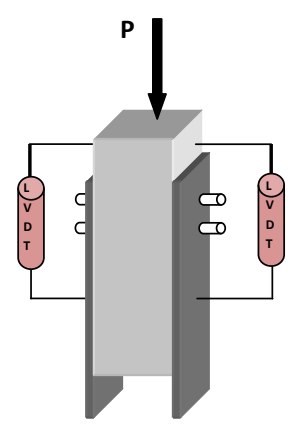

(a)

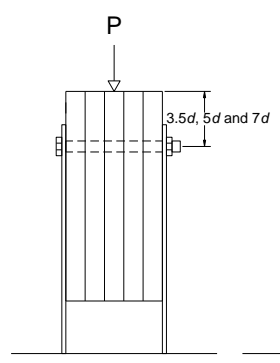

(b)

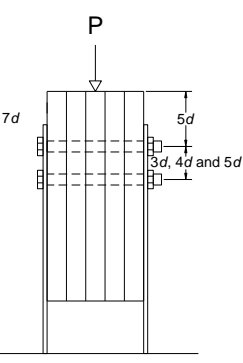

(c)
Figure 2. Connection Test: (a) Test Set-up; (b) Single-bolt Connection; and (c) Two-bolt Connection

Figures $2 \mathrm{~b}$ and $2 \mathrm{c}$ show the connection models adopted to evaluate the minimum end distance and bolts spacing, respectively. In this test, three different lengths of end distance: $3.5 d, 5 d$, and $7 d$, and three different lengths of bolt spacing: $3 d, 4 d$, and $5 d$ were examined. Altogether, there were six connection models which were grouped into: singlebolt connections and two-bolt connections. Five replicates were fabricated for each connection models. In the case of the two-bolt connection models, end distance of the connections was decided based on evaluation of the minimum end distance through single-bolt connection tests. Bolt hole in the LVL member and steel plates were the same and it was equal to bolt diameter plus $1 \mathrm{~mm}$ clearance.

In addition to this connection test, evaluation of dowel bearing strength of LVL members and 
bending yield strength of the bolts were conducted in accordance to ASTM D5764 [14] and ASTM F157503 [15], respectively. In these tests, eight dowel bearing strength specimens and three bolt specimens were prepared.

\section{Results and Discussions}

Under bending test, load-deflection curve of the bolt specimens indicated large ductility index and clear strain hardening after reaching the proportional limit load. Bending yield moment was obtained by means of 5\% bolt diameter offset method [14] and it was found equal to $65.73 \mathrm{kN} . \mathrm{mm}$. While the average dowel bearing strength of LVL members was 20.07 MPa (Maximum 20.35 MPa, Minimum 19.79 MPa). Figure 3 and 4 shows the test results of bending test of bolts and dowel bearing strength of the LVL members.

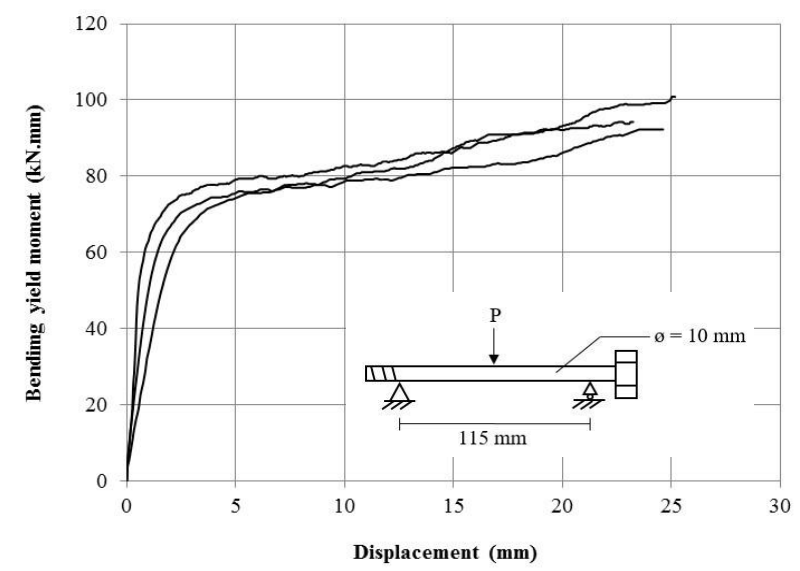

Figure 3. Bending Test Results of the Bolts

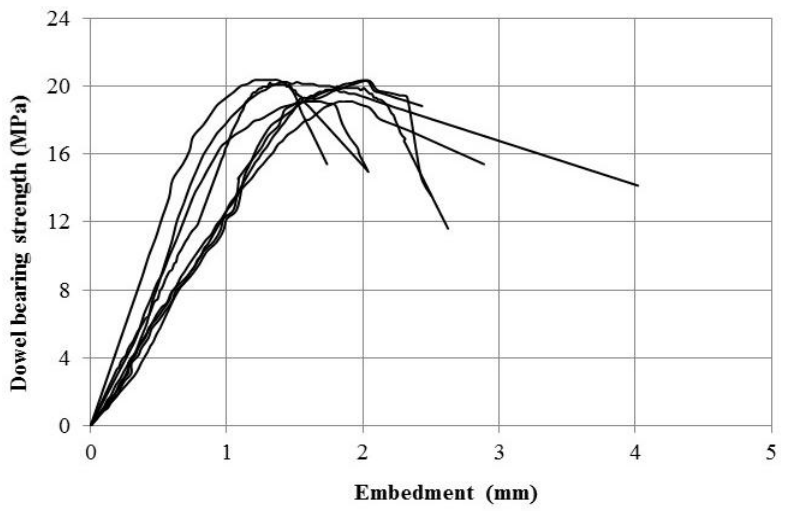

Figure 4. Dowel Bearing Strength of LVL Members

Load-slip curves obtained from the experiment for single-bolt connections are presented in Figures 5a, $5 \mathrm{~b}, 5 \mathrm{c}$, respectively, for three different lengths of end distances: $3.5 d, 5 d$, and $7 d$. Within each load-slip curve, connection yield load and ductility index are defined as follows: Yield load is the load at the intersection point between the curve and an offset line having a slope equals to the initial slope of the curve but this line is shifted by a slip of $5 \%$ of bolt diameter as shown in Figure 6 [16,17]; Ductility index is defined as ratio between the slip at load decreased by $20 \%$ from its maximum load (or at the ultimate load when the curve never reaches $20 \%$ load decrease after its maximum load) and the slip at yield load. Yield load and ductility index of all singlebolt connections are summarized in Table 2 where it is well observed that single-bolt connections with end distance of $3.5 d$ gave the lowest, for both yield load and ductility index. This finding suggests that end distance of $5 d$ would be acceptable as the minimum end distance of LVL bolted connection.

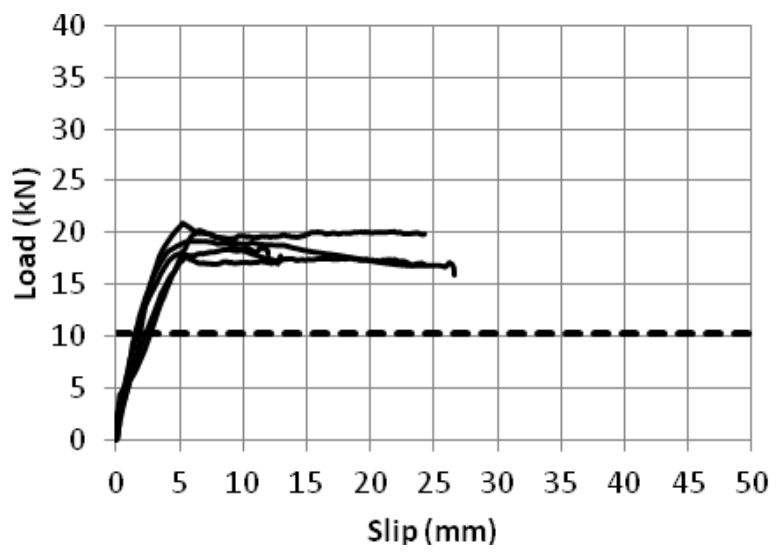

(a) End Distance of $3 d$

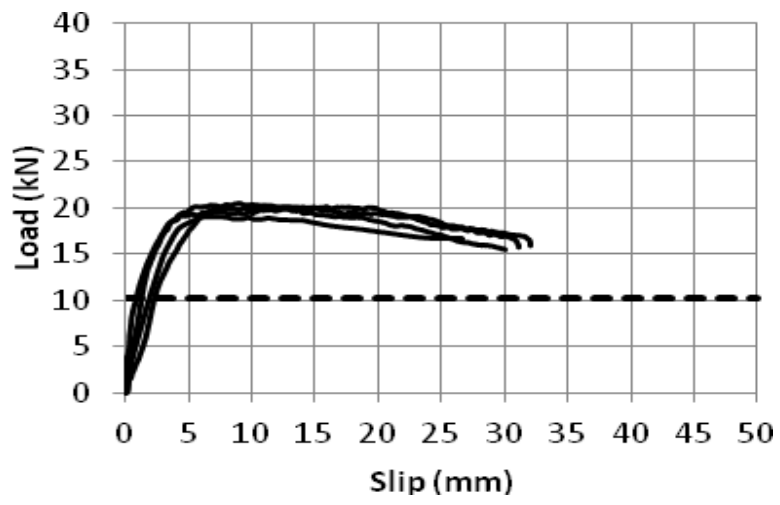

(b) End Distance of $5 d$

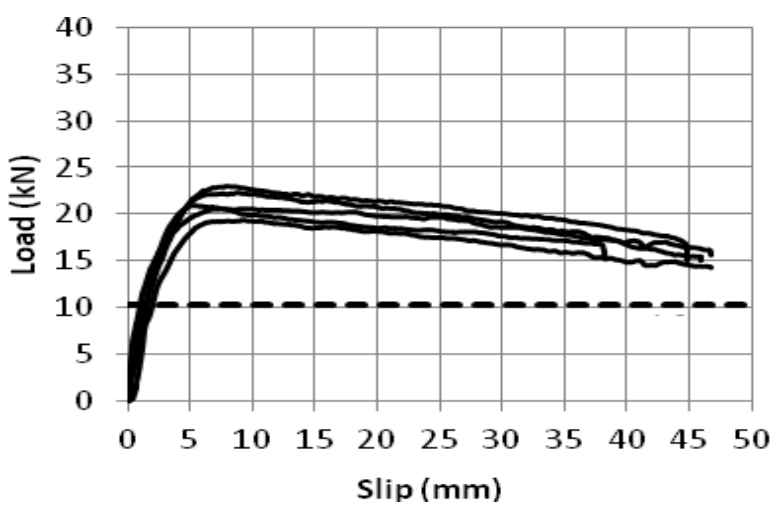

(c) End Distance of $7 d$

Figure 5. Load-slip Curves of Single-bolt Connection for Three Different Lengths of End Distance and EYM Load Carrying Capacity 


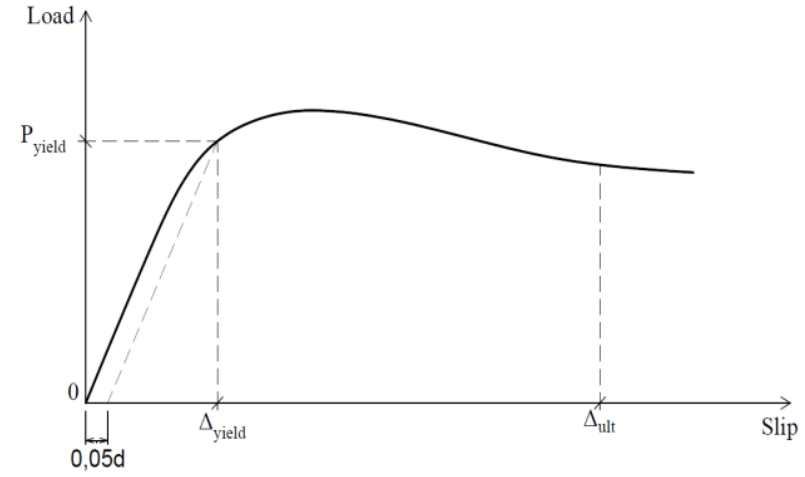

Figure 6. Definition of Yield Load and Ductility Index [16$17]$

Table 2. Yield Load and Ductility Index of the Single-bolt Connection

\begin{tabular}{ccc}
\hline End distance & Yield load $(\mathrm{kN})$ & Ductility index \\
\hline $3.5 d$ & 17.12 & 4.84 \\
$5 d$ & 18.64 & 7.58 \\
$7 d$ & 19.30 & 9.26 \\
\hline
\end{tabular}

Figure 5 shows both experimental results and EYM prediction calculated based on a set of equation given in Table 1. As widely accepted, connection yield load given by EYM is lower than that of the experiment, in this case the ratio is $0.53,0.55$, and 0.60 , respectively, for single-bolt connections with an end distance of $3.5 d, 5 d$, and $7 d$. This is substantially due to frictional resistance developed between interfaces of the connection members as bolt starts to bend. Unfortunately, connection evaluation using FEA based on beam on elastic theory was not conducted since information about load-embedment relationship of the steel plate into LVL member due to bolt's axial force is not available.

Figure 7 shows the load-slip curve of the two-bolt connection specimens for three different bolt spacing: $3 d$; $4 d$; and $5 d$ having an equal end distances, which is $5 d$. Again, these load-slip curves are analyzed to obtain their connection yield loads and ductility indexes as can be seen in Table 3, where it is well observed that ductility index of the two-bolt connections is significantly lower than that of the singlebolt connections (specimens with end distance of $5 d$ ). This is because the tendency of wood failure near the bolts of the two-bolt connections is higher than that of single-bolt connections. The two-bolt connections have possible wood splitting, row shear, and grouptear out failures as well as the combination among these three failure modes, will substantially limit both connection yield load and ductility index. Photos of failure modes of the single-bolt and two-bolt connection specimens are shown in Figure 8, indicating that row shear governed the failure of both single-bolt and two-bolt connection specimens.

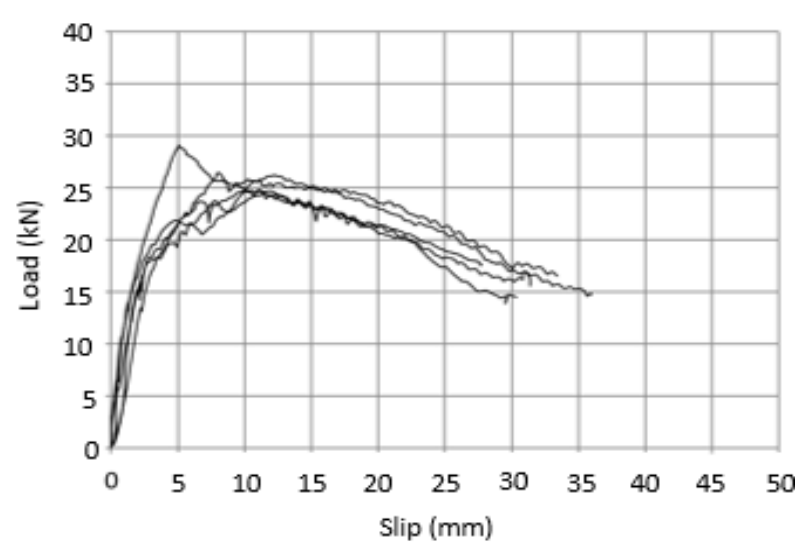

(a) Bolt Spacing of $3 d$

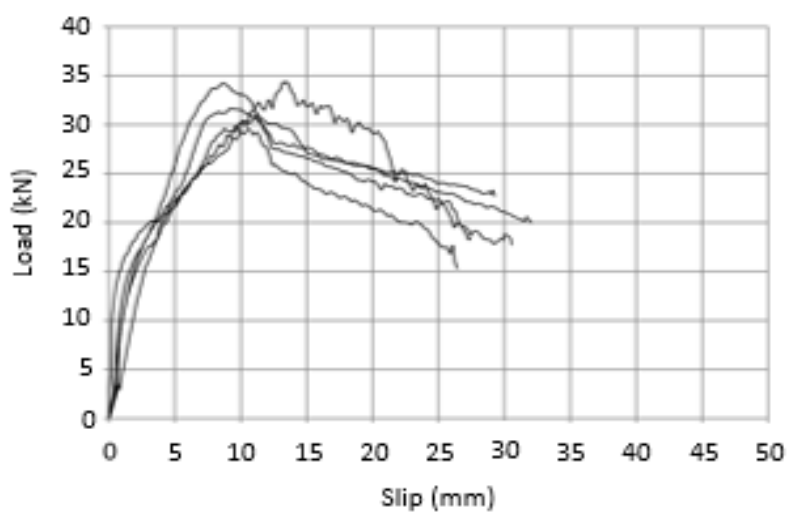

(b) Bolt Spacing of $4 d$

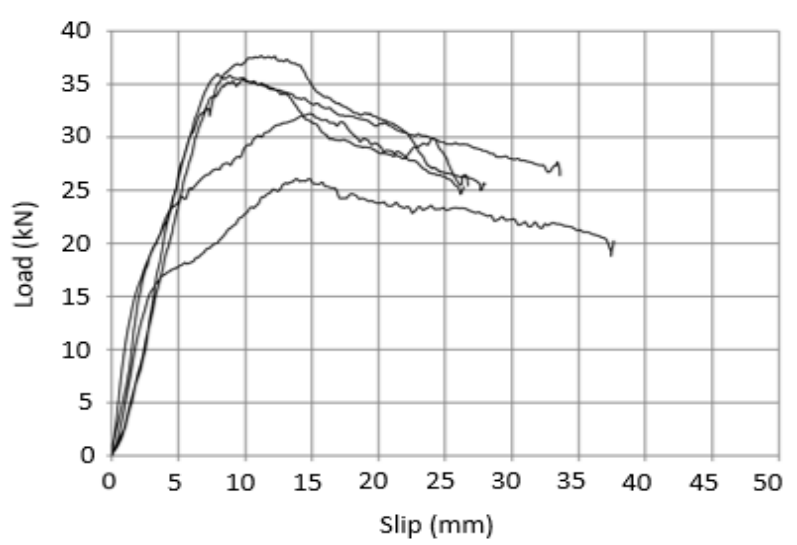

(c) Bolt Spacing of $5 d$

Figure 7. Load-slip Curves of Two Bolt Connection for Three Different Lengths of Bolt Spacing

The yield load of two-bolt connection increases as the bolt spacing is increased from $3 d$ to $5 d$ as shown in Table 3. Comparing the average yield load of the two-bolt connection to the single-bolt connection having similar end distance of $5 d$, it is found ratios equal to $1.01,1.30$, and 1.65, respectively, for the two-bolt connection with bolt spacing of $3 d, 4 d$, and $5 d$. None of the two-bolt connections gave two times yield load of the single-bolt connection. This phenomenom is anticipated in design through group action factor. For this two-bolt connection specimen, number of effective bolts given by Equation 1 is 1.29, 
1.39, and 1.47, respectively, supposing that $a_{1}$ is equaled to $3 d, 4 d$, and $5 d$. Therefore, bolt spacing of $5 d$ should be recommended as the minimum bolt spacing since it is the only one that gives number of effective bolts of prediction (which is 1.47) lower than the ratio between yield load of single-bolt and twobolt connection of the experiment (which is 1.65).
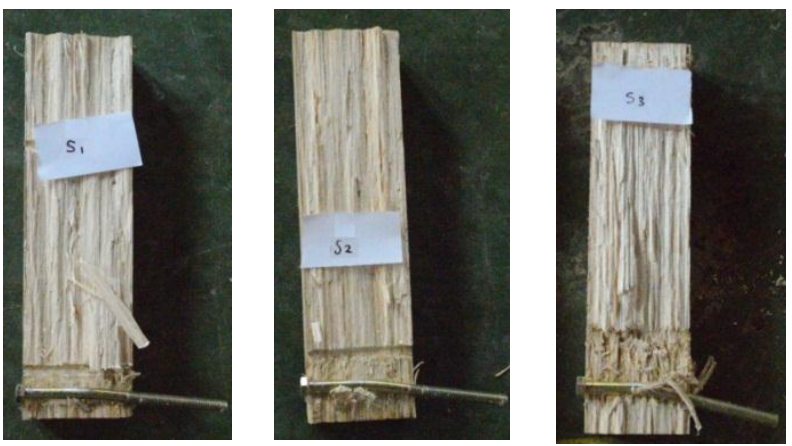

(a) Single-bolt Connection
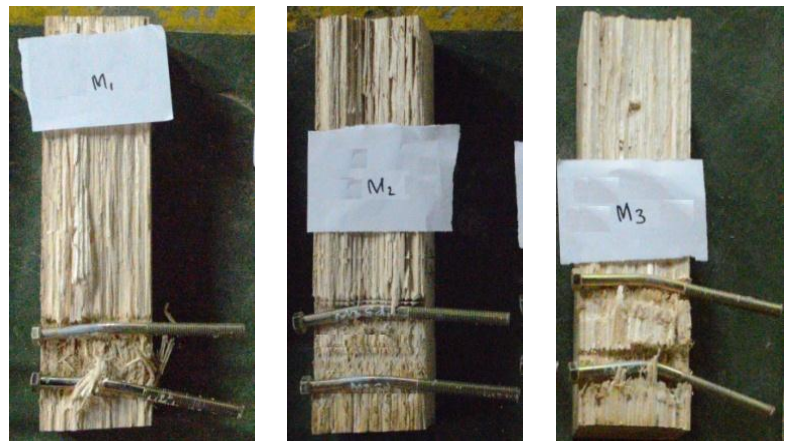

(b) Two-bolt Connections

Figure 8. Typical Failure Modes of the Connections

Table 3. Yield Load and Ductility Index of the Two-bolt Connection

\begin{tabular}{ccc}
\hline Bolt spacing & Yield load $(\mathrm{kN})$ & Ductility index \\
\hline $3 d$ & 18.75 & 6.83 \\
$4 d$ & 23.80 & 4.33 \\
$5 d$ & 30.82 & 3.73 \\
\hline
\end{tabular}

\section{Conclusions}

This study evaluated the minimum end distance and bolt spacing for bolted connections of LVL Sengon, a new emerging and sustainable building material available in Indonesian markets recently. Single-bolt connections with three different end distances: $3.5 d$, $5 d$, and $7 d$, and two-bolt connections with three different bolt spacing: $3 d, 4 d$, and $5 d$ were tested under double-shear connection test set-up (steelwood-steel) where $d$, the bolt diameter, $10 \mathrm{~mm}$. The test results confirmed that $5 d$ should be used as both the minimum end distance and the minimum bolt spacing. In addition, row shear predominantly governed the connection failure mode instead of wood splitting.

\section{Acknowledgements}

The authors wish to thank PT. Sumber Graha Sejahtera for providing LVL Sengon used in this study. Our sincere gratitude also goes to Ms. Khamida Nur Faizah and Mr. Gary Lienatha for their assistance in adjusting layout and template of this paper.

\section{References}

1. Awaludin, A., Development of Structural Walls made from LVL Sengon (Paraserianthes Falcataria): Basic Mechanical Properties, Proceeding of Sustainable Civil Engineering Structures and Construction Materials, Yogyakarta, 2012, pp. 299-302.

2. Awaludin, A., Pribadi, A., and Satyarno, I., Racking Resistance of Paraserianthes Falcataria Wooden Panel under Monotonic Load, Proceeding of the Sixth Civil Engineering Conference in Asia-Pacific Region (CECAR6), Jakarta, paper \# 79, 2013.

3. Awaludin, A. and Astuti, P., Study on Utilization of LVL Sengon (Paraserianthes falcataria) for Three-Hinge Gable Frame Structures, International Journal of Engineering Technology and Innovation (IJETI), 6(3), 2016, pp. 232-241.

4. Johansen, K.W., Theory of Timber Connections, International Association of Bridges and Structural Engineering, Publication (9), Bern, 1949, pp. 249-262.

5. Hirai, T, Analyses of the Lateral Resistance of Bolt Joints and Drift Pin Joints in Timber II: Numerical Analyses Applying the Theory of a Beam on an Elastic Foundation, Journal of Mokuzai Gakkaishi, Japan Wood Research Society, 37, 1991, pp. 1017-1025.

6. Jorissen, A.J.M., 1998, Double Shear of Timber Connections with Dowel Type Fasteners, DUP Delft.

7. Khelifa, M. and Oudjene, M., Elasto-Plastic Constitutive Law for Wood Plastic Behavior under Compressive Loadings, Construction and Building Materials, 23(11), 2009, pp. 3359-3366.

8. Prion, H. and Foschi, R., Cyclic Behavior of Dowel Type Connections, Proceeding of The Pacific Timber Engineering Conference, Gold Coast Australia, Vol 2, 1994, pp. 19-25.

9. Awaludin, A., Static and Dynamic Behavior of Bolted Timber Joints with Steel Splice Plates, Ph.D Thesis, Hokkaido University, Japan, 2008.

10. Awaludin, A., Hayashikawa, T., Oikawa, A., Hirai, T., Sasaki, Y., and Leijten, A.J.M., Seismic Properties of Moment-Resisting Timber Joints with a Combination of Bolts and Nails, Civil Engineering Dimension, 13(1), 2011, pp. 1-5. 
11. Haller, P. and Wehsener, J., Use of Technical Textiles and Densified Wood for Timber Joints, World Conference on Timber Engineering, Oregon, 2006.

12. Blass, H.J., Schmid, M., Litze, H., and Wagner, B., Nail Plate Reinforced Joints with Dowel Type Fastener, World Conference on Timber Engineering, Oregon, 2006.

13. Tsujino, T., Hirai, T., and Takeuchi, N., Analyses of the Lateral Resistance of Bolt Joints and Drift Pin Joints in Timber III: Numerical Analyses Applying the Finite Element Method (In Japanese), Journal of Mokuzai Gakkaishi, Japan Wood Research Society , 49(3), 2003, pp. 187-196.
14. ASTM D5764-97a(2013), Standard Testing Method for Evaluating Dowel-bearing Strength of Wood-based Products, ASTM International, West Conshohocken, PA, 2013, www.astm.org

15. ASTM F1575-03(2003), Standard Test Method for Determining Bending Yield Moment of Nails, ASTM International, West Conshohocken, PA.

16. Awaludin, A., Smittakorn, W., Hirai, T., and Hayashikawa, T., Bearing Properties of Shorea Obtusa beneath a Laterally Loaded Bolt, Journal of Wood Science, 53(6), 2007, pp. 204210.

17. Awaludin, A., Hirai, T., Hayashikawa, T., and Sasaki, Y., Load-carrying Capacity of Steel-toTimber Joints with a Pretensioned Bolt, Journal of Wood Science, 54(3), 2008, pp. 362-368. 